Article

\title{
An Adaptive Offset Tracking Method with SAR Images for Landslide Displacement Monitoring
}

\author{
Jiehua Cai ${ }^{1}$, Changcheng Wang ${ }^{1,2, *} \mathbb{B}$, Xiaokang Mao ${ }^{3}$ and Qijie Wang ${ }^{1}$ \\ 1 School of Geosciences and Info-Physics, Central South University, Changsha 410083, China; \\ caijiehua@csu.edu.cn (J.C.); qjwang@csu.edu.cn (Q.W.) \\ 2 Key Laboratory of Metallogenic Prediction of Nonferrous Metals and Geological Environment Monitoring, \\ Ministry of Education, Central South University, Changsha 410083, China \\ 3 China Railway Siyuan Survey and Design Group Company, Wuhan 430063, China; 006094@crfsdi.com \\ * Correspondence: wangchangcheng@csu.edu.cn; Tel.: +86-731-8883-0573
}

Academic Editors: Zhong Lu, Zhenhong Li, Roberto Tomas and Richard Gloaguen Received: 15 July 2017; Accepted: 9 August 2017; Published: 11 August 2017

\begin{abstract}
With the development of high-resolution Synthetic Aperture Radar (SAR) systems, researchers are increasingly paying attention to the application of SAR offset tracking methods in ground deformation estimation. The traditional normalized cross correlation (NCC) tracking method is based on regular matching windows. For areas with different moving characteristics, especially the landslide boundary areas, the NCC method will produce incorrect results. This is because in landslide boundary areas, the pixels of the regular matching window include two or more types of moving characteristics: some pixels with large displacement, and others with small or no displacement. These two kinds of pixels are uncorrelated, which result in inaccurate estimations. This paper proposes a new offset tracking method with SAR images based on the adaptive matching window to improve the accuracy of landslide displacement estimation. The proposed method generates an adaptive matching window that only contains pixels with similar moving characteristics. Three SAR images acquired by the Jet Propulsion Laboratory's Uninhabited Aerial Vehicle Synthetic Aperture Radar (UAVSAR) system are selected to estimate the surface deformation of the Slumgullion landslide located in the southwestern Colorado, USA. The results show that the proposed method has higher accuracy than the traditional NCC method, especially in landslide boundary areas. Furthermore, it can obtain more detailed displacement information in landslide boundary areas.
\end{abstract}

Keywords: landslide; normalized cross correlation; offset tracking; adaptive matching window

\section{Introduction}

A landslide is a kind of destructive geological disaster that causes enormous economic losses and threatens human lives [1]. Therefore, it is necessary to monitor landslide displacement for preventing hazards and mitigating losses. Remote sensing is a rapid and accurate tool that has been used in monitoring landslides for decades [2,3]. As an active remote sensing technology, Synthetic Aperture Radar (SAR) can work under any weather and illumination conditions [4]. It has been widely used in many different applications, such as topography inversion [5,6], forest investigation $[7,8]$, ocean observation [9] and geohazards monitoring [10-14]. For landslide monitoring, the differential interferometric SAR (D-InSAR) technology and the offset tracking method with SAR images have been widely used. The D-InSAR technology can monitor ground deformation with high precision. However, it only measures the deformation along the line-of-sight (LOS) direction, and cannot measure deformation exceeding the maximum detectable deformation gradient $[15,16]$. The offset tracking method can measure large deformations along both the azimuth and range directions, but its precision is determined by the resolution of SAR images [17]. Now, the resolutions of spaceborne SAR systems 
(e.g., TerraSAR-X [18] and Cosmo-SkyMed [19]) have been improved to sub-meter level, such as the Staring Spotlight Mode of TerraSAR-X, which has the resolution of 0.25 meter. Airborne SAR systems can also provide higher resolution data. Therefore, the offset tracking method with SAR images is widely applied in monitoring coseismic displacement [20-25], glaciers [26-30], landslides [31,32] and volcanoes [33].

The offset tracking method with SAR images has two ways to compute offsets: coherence tracking and intensity tracking [34]. Coherence tracking, also known as the coherence optimization procedure or fringe visibility algorithm, uses local coherence maximization to generate matching results [35]. Intensity tracking only uses the intensity information of SAR images. The normalized cross correlation (NCC) method is a classical intensity offset tracking method [36,37]. With the development of polarimetric SAR, researchers used the polarimetric information to improve the precision of offset tracking. Erten et al. proposed the maximum likelihood (ML) texture tracking to monitor the Inylchek glacier velocity [38], which is more stable and reliable than the single channel offset tracking. Then, he proposed a new polarimetric tracking method based on the mutual information (MI), and estimated the velocity of the Aletsch Glacier [39]. Casu et al. combined the Small Baseline Subset (SBAS) inversion strategy and offset tracking method to retrieve the time-series displacement of the Sierra Negra caldera [33]. After that, Hu et al. proposed a method that performs offset tracking on detected point-like targets to improve the method's efficiency and reliability [40]. Wang et al. improved the reliability and accuracy of SAR offset tracking by identifying strong reflectors and estimating their offsets [25]. Wang et al. proposed a method with the polarimetric normalized inner product (PolNIP) [41]. Liu et al. proposed an adaptive NCC method for monitoring soil displacements with optical digital images, which divides the matching template into small patches, in order to improve the accuracy [42]. However, these methods are for calculating the correlation between two regular image patches and finding the maximum correlation [40]. So, they cannot get accurate displacement results for landslide boundary areas, as the regular matching windows located in the landslide's boundary areas always contain two kinds of pixels with different moving characteristics. One type is moving pixels from the sliding region, and the other type is stable pixels. The moving parts and the stable parts in the regular matching windows from two temporal SAR images will affect the statistical correlation and the matched point's offsets value. Therefore, the results for areas near the landslide boundary will be incorrect, especially with large matching windows. To address this problem, a new offset tracking method based on adaptive normalized cross correlation (ANCC) is proposed in this paper. The ANCC method generates an irregular matching window that only includes pixels with similar moving characteristics to those of the pixel under test. This strategy improves the accuracy of the displacement estimation, especially for landslide boundary areas. We select two pairs of L-band SAR images covering the Slumgullion landslide located in the San Juan Mountain of Colorado, USA to validate the proposed method. These images were acquired by the Jet Propulsion Laboratory's Uninhabited Aerial Vehicle Synthetic Aperture Radar (UAVSAR) [43].

The paper is organized as follows. Section 2 introduces the traditional NCC method, and describes the principle of the new adaptive offset tracking method. Section 3 presents the experimental results. In Section 4, we discuss the performance of the proposed method. Finally, we draw conclusions in Section 5.

\section{Methodology}

\subsection{The Traditional NCC Tracking Method}

The traditional NCC tracking method estimates horizontal displacements by calculating the offsets between two images covering the same place. It finds the best match by maximizing the normalized cross correlation of two regular image patches of two images [44]. Figure 1 shows the 
schematic of the traditional NCC tracking method. The normalized cross correlation is defined in Equation (1).

$$
\rho=\frac{\left|\sum_{i=1}^{M} \sum_{j=1}^{N}\left(m_{i, j}-\mu_{m}\right)\left(s_{i, j}-\mu_{s}\right)\right|}{\sqrt{\sum_{i=1}^{M} \sum_{j=1}^{N}\left(m_{i, j}-\mu_{m}\right)^{2}} \sqrt{\sum_{i=1}^{M} \sum_{j=1}^{N}\left(s_{i, j}-\mu_{s}\right)^{2}}}
$$

where the template size is $M \times N, i \in\{1,2, \ldots, M\}$ and $j \in\{1,2, \ldots, N\} . m_{i, j}$ and $s_{i, j}$ are intensity values at pixel $(i, j)$ within the template of the master image (IM) and the slave image (IS), respectively. $\mu_{m}$ and $\mu_{s}$ are the mean of the template of IM and IS, respectively.

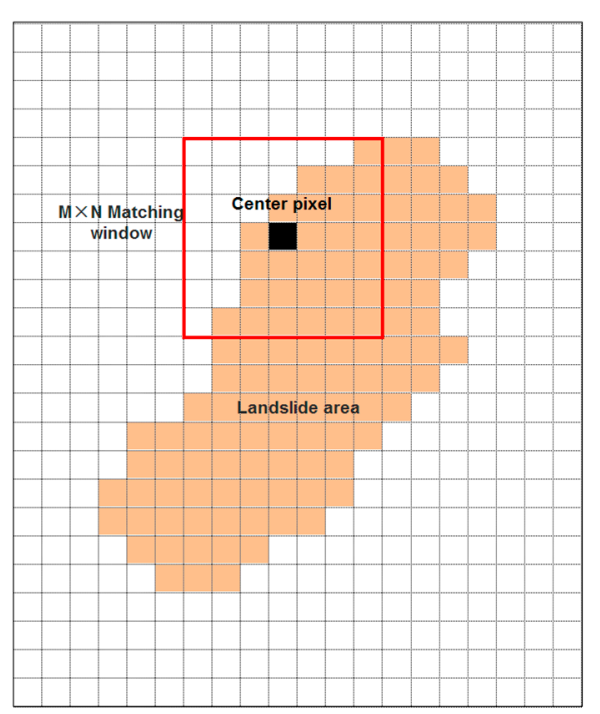

(a)

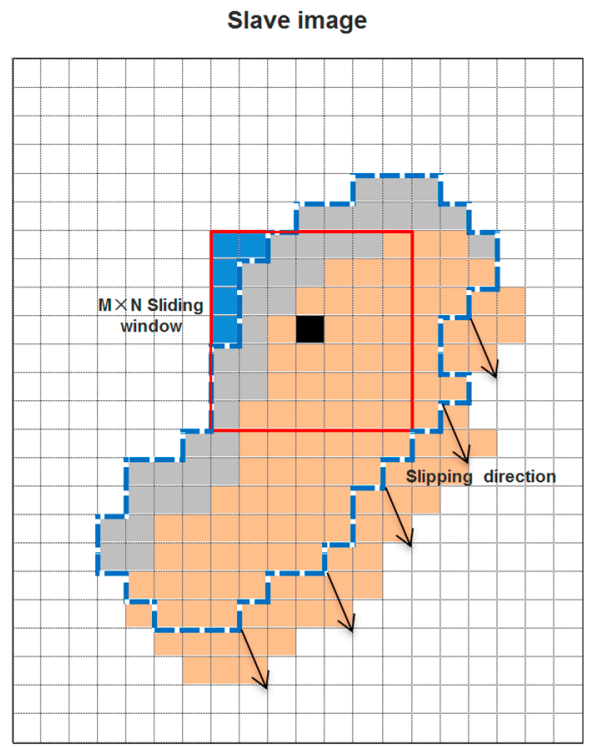

(b)

Figure 1. The schematic of traditional normalized cross correlation (NCC) tracking method. (a) the master image, (b) the slave image. The white and blue pixels in (b) come from stable areas, the orange pixels come from moving areas, and the gray pixels are newly emerged area because of sliding.

Figure 1 shows that the regular matching template (red rectangle) contains pixels from both the stable (white pixels) and sliding areas (orange pixels) when it locates on the boundaries of the landslide. When the pixel under test is located in the moving area, as shown in Figure 1b, the white and gray pixels within the red rectangle will be decorrelated with the white pixels (within the red rectangle) in Figure 1a. Then, the normalized cross correlation of two matching windows will decrease significantly, which will affect the position of the normalized cross correlation plane's peak. Therefore, it will reduce the accuracy of the offsets estimation when the pixel under test is located in the landslide boundaries. In addition, the above problem becomes worse when the size of the matching templates increases, at which point the affected area also becomes larger.

\subsection{The Proposed Adaptive Normalized Cross Correlation (ANCC) Method}

For solving the above problems, we generate an adaptive matching window containing similar moving characteristics with the pixel under test by the proposed offset tracking method. In this adaptive matching window, the pixel under test is either located in the moving area or the stable area. As shown in Figure 2, the pixels within the adaptive window (indicated by the red polygons) are all from the sliding area. Then, we compute the correlation value using the Equation (2).

$$
\rho=\frac{\left|\sum_{(i, j) \in W}\left(m_{i, j}-\mu_{m}\right)\left(s_{i, j}-\mu_{s}\right)\right|}{\sqrt{\sum_{(i, j) \in W}\left(m_{i, j}-\mu_{m}\right)^{2}} \sqrt{\sum_{(i, j) \in W}\left(s_{i, j}-\mu_{s}\right)^{2}}}
$$


$W$ is the pixel sets in the adaptive matching window, $(i, j) \in W . m_{i, j}$ and $s_{i, j}$ are intensity values at pixel $(i, j)$ within the template of IM and IS, respectively. $\mu_{m}$ and $\mu_{s}$ are the mean of the template of IM and IS, respectively.

This strategy can eliminate the decorrelation caused by the different types of moving characteristics within the matching windows. Therefore, it will increase the correlation value of the best matched position and improve the accuracy of the offsets estimation.

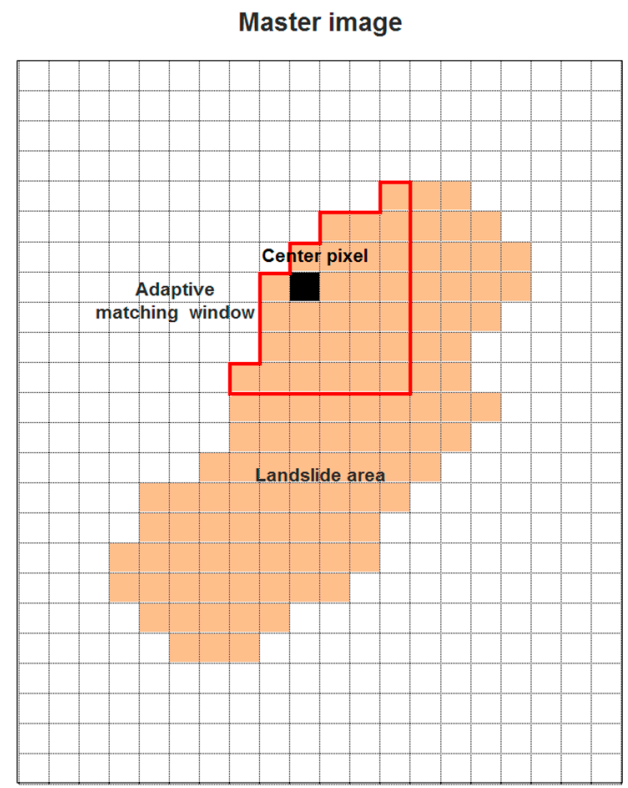

(a)

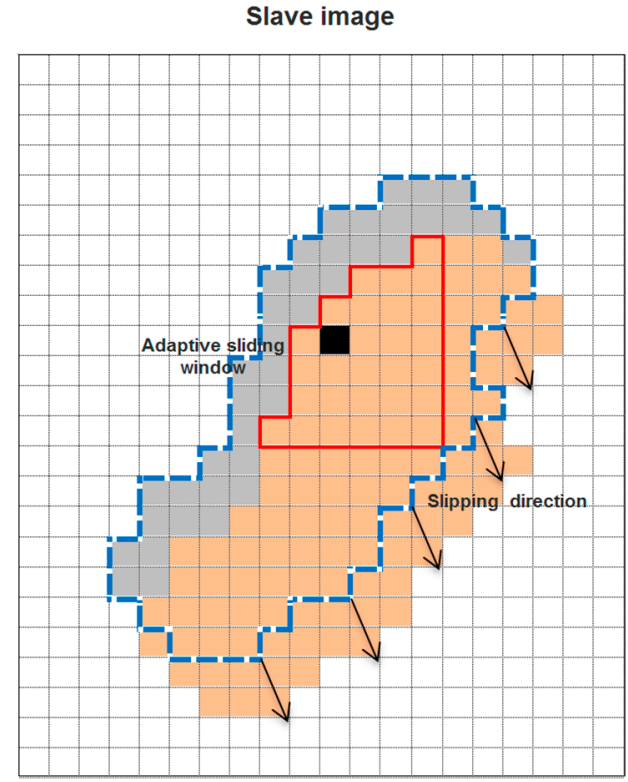

(b)

Figure 2. The schematic of the adaptive normalized cross correlation (ANCC) algorithm. (a) the master image, (b) the slave image. The black point indicates the pixel under test. The white pixels represent the stable area without displacement, and the orange pixels represent the moving area.

However, how to generate the adaptive window is the key step. As we cannot get the priori information for the exact boundaries of the landslide, we first get an initial azimuth and range offsets estimation results by using the traditional NCC method based on a regular matching template, as shown in Figure 1. Then, we use these results to generate two mask results in azimuth and range direction, respectively. The results with offsets larger than a threshold are defined as the moving area, and the rest of the results are the stable area. According to the above mask results, when the pixel under test locates in the moving area, as shown in Figure 2, we only choose the pixels belonging to the moving area defined by the mask results (indicated by the red polygons) for computing the correlation values. As shown in Figure 3, the detailed steps are as follows:

(1) Making a rough co-registration for master and slave SAR images;

(2) Calculating initial azimuth and range offsets between master and slave SAR images using the traditional NCC method;

(3) Thresholding the azimuth and range offsets and generating two corresponding mask images;

(4) Estimating azimuth and range offsets by using an adaptive window guided by the mask images;

(5) Fitting the orbit offsets function with the pixels from stable areas determined by the above mask results;

(6) Subtracting the fitted orbit offsets and generating azimuth and range displacements by multiplying the corresponding pixel spacing. 


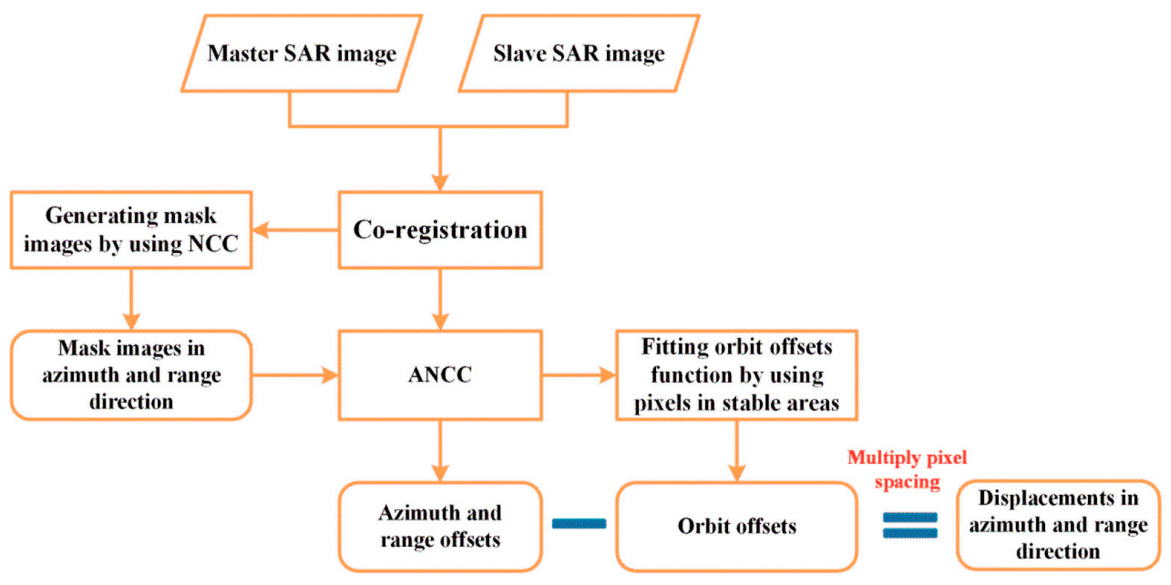

Figure 3. Flowchart of the proposed ANCC method.

\section{Study Area and Experimental Results}

In order to validate the proposed method, the Slumgullion landslide $\left(37^{\circ} 59^{\prime} 30^{\prime \prime} \mathrm{N}, 107^{\circ} 15^{\prime} 25^{\prime \prime} \mathrm{W}\right)$ located in the San Juan Mountains of Colorado, USA is selected as the study area. Figure 4a shows the optical image of the study area. The active part of this landslide is about $3.9 \mathrm{~km}$ long, and its widths range from $100 \mathrm{~m}$ to $500 \mathrm{~m}$ [45]. The surface elevation of the landslide ranges from $2750 \mathrm{~m}$ to $3650 \mathrm{~m}[46,47]$. The great altitude difference causes the continuous sliding for hundreds of years. Scientists have done many studies in this area [48-52]. These studies indicate that the Slumgullion landslide have a maximum velocity of about $1 \mathrm{~cm} /$ day [51,52]. These estimates are based on the D-InSAR method and SAR images with intervals of several days or weeks. However, for a long time span, the displacements of the Slumgullion landslide far exceed the maximum detectable deformation of the D-InSAR method. Therefore, the offset tracking method is more suitable for monitoring the landslide with larger displacements. This paper selected three L-band SAR intensity images acquired by the JPL's UAVSAR system to estimate the displacement of the Slumgullion landslide. Figure $4 \mathrm{~b}$ illustrates the UAVSAR intensity image acquired on 19 August 2011. The detailed information of the images is as shown in Table 1. We mainly select the first two UAVSAR images for experiments and analysis. These two images were acquired within an interval of 265 days. The GPS observations that were used to validate the results were acquired between 1 August 2011 and 10 April 2012.

Table 1. The detailed information of the Uninhabited Aerial Vehicle Synthetic Aperture Radar (UAVSAR) images.

\begin{tabular}{ccccc}
\hline Acquired Time & Polarization & Azimuth Pixel Spacing & Range Pixel Spacing & Wavelength \\
\hline 19 August 2011 & $\mathrm{HH}$ & $0.60 \mathrm{~m}$ & $1.67 \mathrm{~m}$ & $23.84 \mathrm{~cm}$ \\
9 May 2012 & $\mathrm{HH}$ & $0.60 \mathrm{~m}$ & $1.67 \mathrm{~m}$ & $23.84 \mathrm{~cm}$ \\
1 August 2012 & $\mathrm{HH}$ & $0.60 \mathrm{~m}$ & $1.67 \mathrm{~m}$ & $23.84 \mathrm{~cm}$ \\
\hline
\end{tabular}

Figure 5 shows the estimated velocities of the Slumugllion landslide by the proposed method with UAVSAR images on 19 August 2011 and 9 May 2012. The displacement results are shown in the radar coordinate system. The initial azimuth and range mask maps (as shown in Figure 6) for judging moving characteristics and determining the adaptive matching windows are estimated by the traditional NCC method. The thresholds used for generating mask images of the azimuth and range offsets are 0.2 pixel and 0.1 pixel, respectively. According to Figure 5, the velocity of Slumgullion landslide is large in the middle, and small in the head and end of the landslide. In the middle area, the maximum sliding rate is about $1 \mathrm{~cm} /$ day, so the total displacement is about $270 \mathrm{~cm}$ during the interval time. The average rates of the head and end of the Slumgullion landslide are 
$0.14-0.25 \mathrm{~cm} /$ day and of $0.4-0.5 \mathrm{~cm} /$ day, respectively. Moreover, we compare the results with other studies on the Slumgullion landslide. As shown in Schulz et al. [45] and Milillo et al. [51], the average sliding velocity in the hopper and neck area of the Slumgullion landslide is approximately $1 \mathrm{~cm} / \mathrm{day}$, which is consistent with the proposed method. In addition, Delbridge et al. [52] demonstrated that the landslide achieved the greatest velocities in April, with a mean velocity of $0.91 \pm 0.26 \mathrm{~cm} /$ day. These results are greater than the results of the proposed method, because the velocity would increase in spring and summer with the increase of snowmelt and precipitation [47]. The results of the proposed method, which are the average velocities during the period of August 2011 to May 2012, are lower than the mentioned velocity in April.

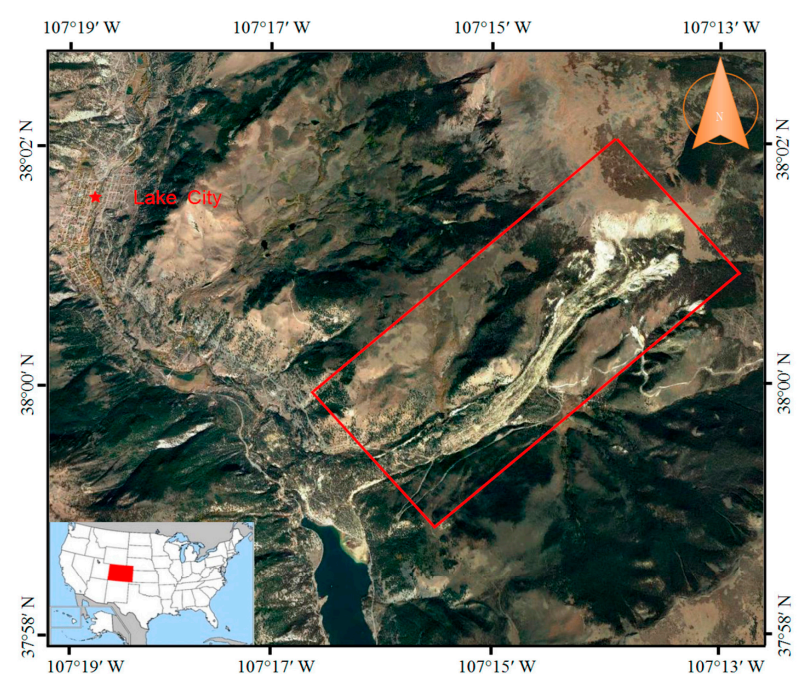

(a)

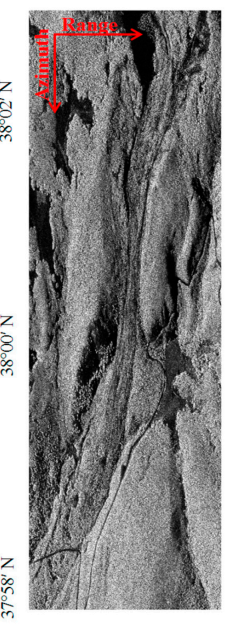

(b)

Figure 4. The optical image (a) from Google Earth $\left({ }^{\circledR}\right.$ Google) and the UAVSAR intensity image (b) of the Slumgullion landslide.
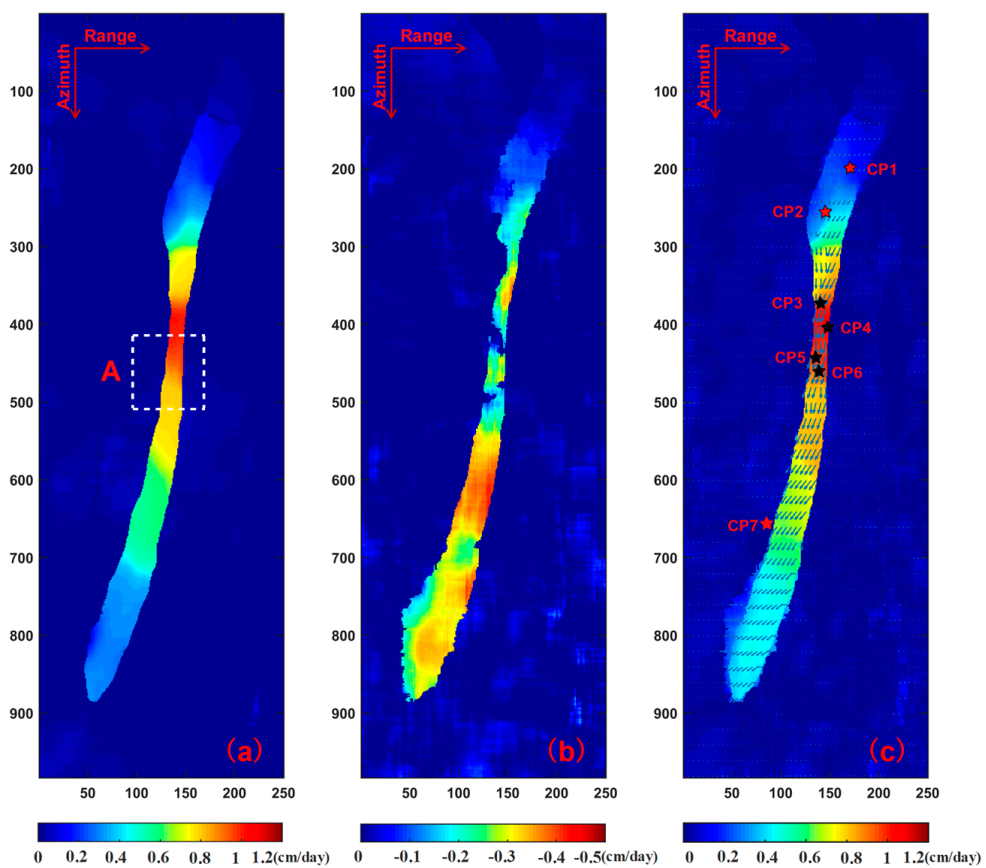

Figure 5. The average velocities of the Slumugllion landslide by using the proposed ANCC method with UAVSAR images on 19 August 2011 and 9 May 2012. (a) The azimuth velocities; (b) the range velocities; (c) the $2 \mathrm{D}$ velocities. 

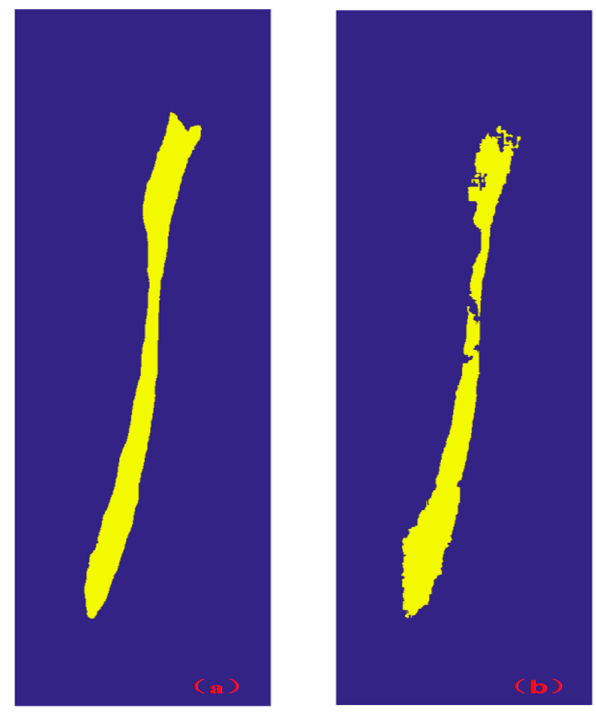

Figure 6. Mask images for determining adaptive matching windows in the proposed ANCC method. They are extracted from initial results by the NCC method. (a) The azimuth direction; (b) the range direction.

\section{Discussion}

This section compares the proposed ANCC method and the classical NCC method in terms of offsets estimation accuracy and the stability of the offsets estimation under different matching window sizes.

\subsection{Accuracy Assessment of the Offsets Estimation}

The cross-correlation quality has significant influence on the accuracy of the pixel-offset measurement [25]. Therefore, the normalized cross-correlation coefficient is used to evaluate the accuracy of the offsets estimation for the proposed ANCC method. The matching algorithm finds the best match by maximizing the correlation of two image patches. The larger the correlation value, the better the accuracy of offsets estimation. As shown in Figure 7, we make a comparison for the differences of the correlation coefficients for the best matched point between the proposed ANCC and the traditional NCC methods. Figure 7a,b shows the correlation coefficients of the ANCC method in the azimuth direction $\rho_{\text {azi }}$ (ANCC) and range direction $\rho_{\text {rng }}$ (ANCC), respectively. Figure 7c is the normalized cross-correlation coefficients of the NCC method $\rho(\mathrm{NCC})$. Figure $7 \mathrm{~d}$-e represent the differences $\rho_{\text {azi }}$ (ANCC) $-\rho\left(\right.$ NCC) and $\rho_{\text {rng }}($ ANCC $)-\rho($ NCC $)$, respectively. For the boundaries of the landslide, the correlation coefficients in both azimuth and range directions for the proposed ANCC are larger than that of the NCC method by about 0.05 to 0.10 . The main reason is that the NCC method uses the regular matching windows to calculate the correlation coefficients, which always contain pixels from both the stable and sliding area. In this case, the correlation coefficients decrease significantly. However, the proposed ANCC method uses the adaptive matching windows, which only contain pixels with similar moving characteristics. Therefore, the ANCC method can get more accurate displacements for the landslide, especially in the boundaries of the landslide.

We make a comparison with the results estimated by GPS, ANCC and NCC, respectively. The locations of the GPS stations (CP 1-CP 7) are shown in Figure 5c. For comparison, the GPS monitoring results are transformed into the radar coordinate system. The GPS monitoring results are acquired from 1 August 2011 to 10 April 2012. As shown in Figure 8, the results estimated by ANCC are in consistence with the GPS monitoring results both in the azimuth and range directions, and the NCC results are approximately the same with the GPS results, except for CP 4. It is worth noting that $\mathrm{CP} 4$ is located in the landslide boundaries (Figure 5c). The velocity of CP 4 estimated by the classical 
NCC is close to $0 \mathrm{~cm} /$ day, both in the azimuth and range directions, but the velocity monitored by GPS is approximately 1.12 and $-0.16 \mathrm{~cm} /$ day in the azimuth and range direction, respectively. It is evident that the ANCC is more accurate than the classical NCC in monitoring displacement on the landslide boundary.

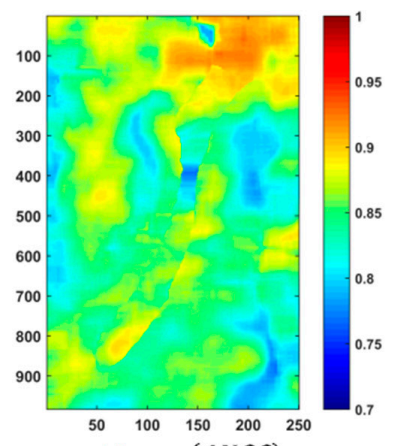

(a) $\rho_{a z i}(A N C C)$

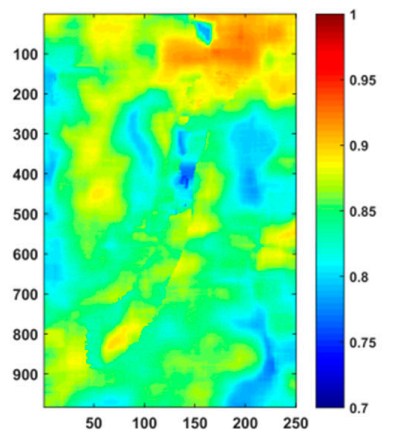

(b) $\rho_{\text {rng }}($ ANCC $)$

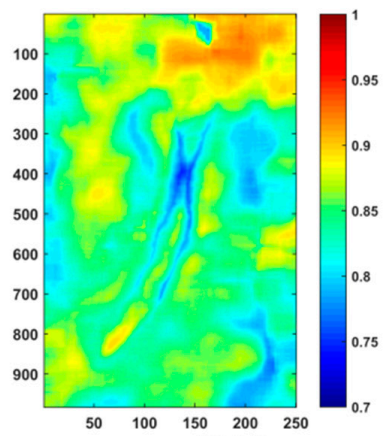

(c) $\rho(N C C)$

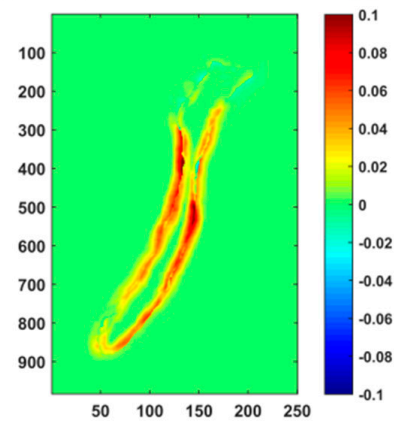

(d) $\rho_{a z i}(A N C C)-\rho(N C C)$

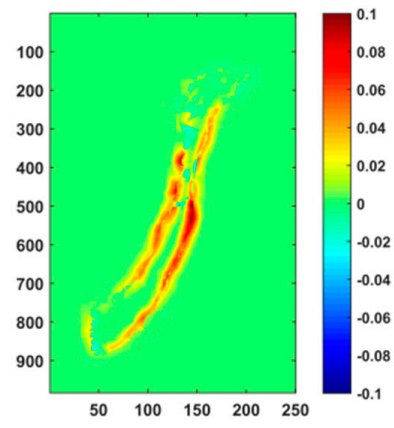

(e) $\rho_{\text {rng }}(A N C C)-\rho(N C C)$

Figure 7. The differences of the correlation coefficients for the best matched point between the proposed ANCC and the traditional NCC methods. (a) The correlation coefficients of the ANCC method for azimuth direction $\rho_{\text {azi }}$ (ANCC); (b) the correlation coefficients of the ANCC method for range direction $\rho_{\text {rng }}($ ANCC); (c) the normalized cross-correlation coefficients of the NCC method $\rho(\mathrm{NCC})$; (d) $\rho_{\text {azi }}($ ANCC $)-\rho($ NCC $)$; (e) $\rho_{\text {rng }}($ ANCC $)-\rho($ NCC $)$.
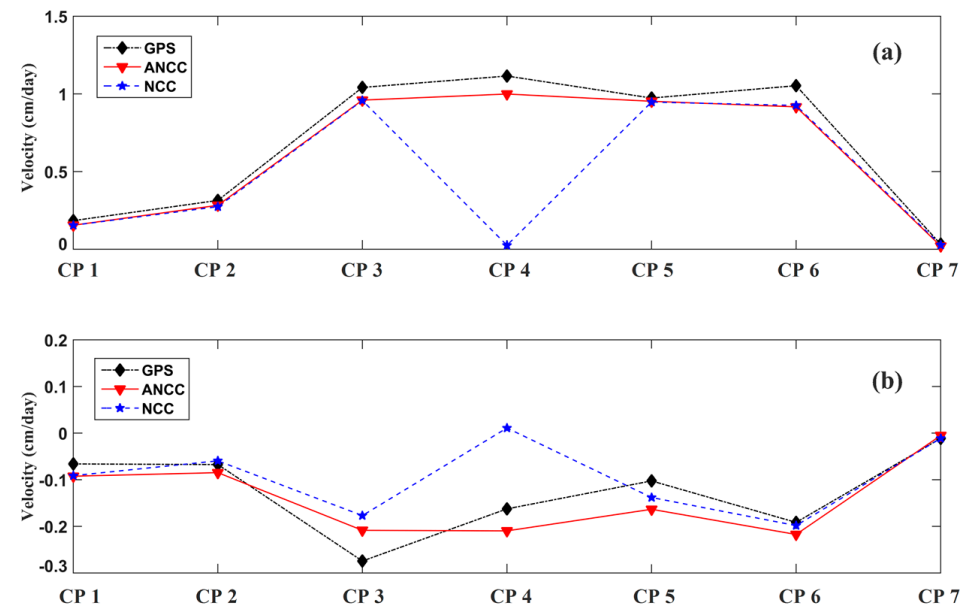

Figure 8. The comparison of velocities in azimuth direction (a) and range direction (b) between GPS, classic NCC, and the proposed ANCC methods. The black dash line indicates the velocity estimated by GPS, the red solid line indicates the velocity estimated by ANCC, and the blue dash line indicates the velocity estimated by classic NCC. 


\subsection{Stability Evaluation with Different Size of Matching Windows}

As mentioned above, the classical NCC offset tracking method cannot eliminate the effect of reduction caused by different moving characteristics within the regular matching windows, especially for the boundary area of the landslide. For improving the accuracy, it always increases the size of the matching windows, which obscures detailed information regarding the displacement. The proposed ANCC method can solve this problem by using the adaptive matching windows, which choose pixels with similar moving characteristics.

For evaluating the stability of the traditional NCC and the proposed ANCC methods, we compute the results of these two methods under different size-matching windows. Figure 9 shows the azimuth displacements of the rectangle A in Figure 5 during the period of 19 August 2011 to 9 May 2012. Figure $9 a-c$ shows the results of the NCC method with the matching window of $129 \times 49,193 \times 73$, and $257 \times 97$ pixels, respectively. The results show that the displacements near the boundaries of the landslide become more blurred with the increasing matching window size. As shown in Figure 10a-c, the profiles along lines $\mathrm{K} 1, \mathrm{~K} 2$ and $\mathrm{K} 3$ present that the edges of the azimuth displacements are changing with the increasing matching window size. In contrast, Figure $9 \mathrm{~d}-\mathrm{f}$ presents the azimuth displacements of the proposed ANCC method with the matching window of $129 \times 49,193 \times 73$, and $257 \times 97$ pixels, respectively. The results under different size-matching windows show similar azimuth displacements near the boundaries of the landslide. Also, as shown in Figure $10 \mathrm{~d}-\mathrm{f}$, all the profiles along lines $\mathrm{K} 1, \mathrm{~K} 2$ and $\mathrm{K} 3$ present similar characteristics, especially at the edges of the azimuth displacements. Compared with the NCC method, the proposed ANCC method can provide more stable estimations for azimuth displacements.

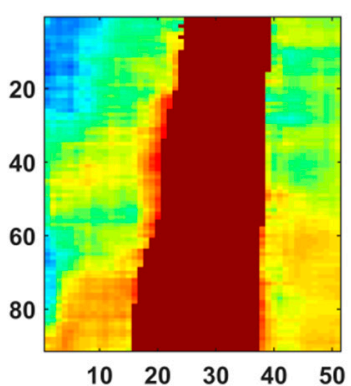

$\begin{array}{rr}10 \quad 20 & 30 \\ & (\mathrm{a})\end{array}$

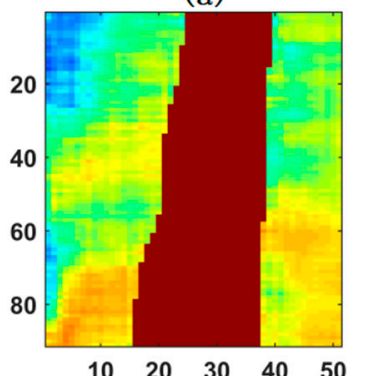

(d)

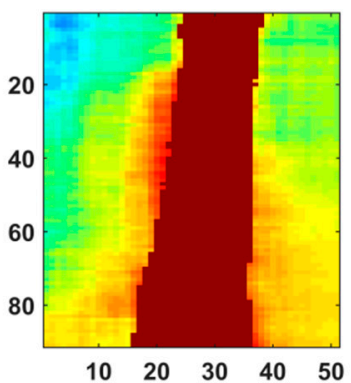

(b)

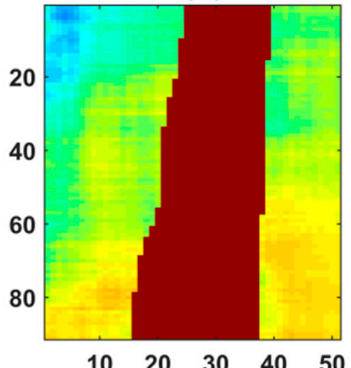

(e)

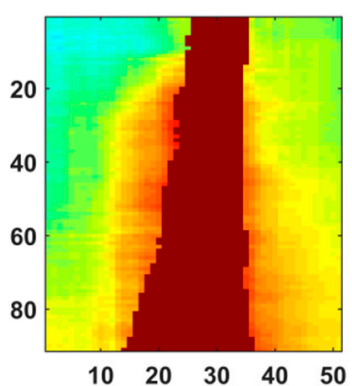

(c)

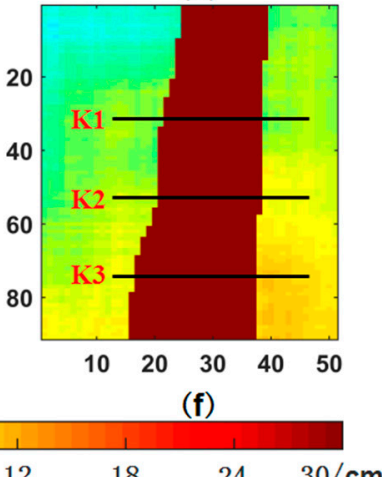

Figure 9. The azimuth displacements (19 August 2011 to 9 May 2012) of sub-area A in Figure 5c. The displacements are estimated by the classical NCC method $(\mathbf{a}-\mathbf{c})$ and the proposed ANCC method $(\mathbf{d}-\mathbf{f})$ under different sizes of matching window, $129 \times 49,193 \times 73$, and $257 \times 97$ pixels. The displayed range is readjusted to $(-30,30) \mathrm{cm}$. 

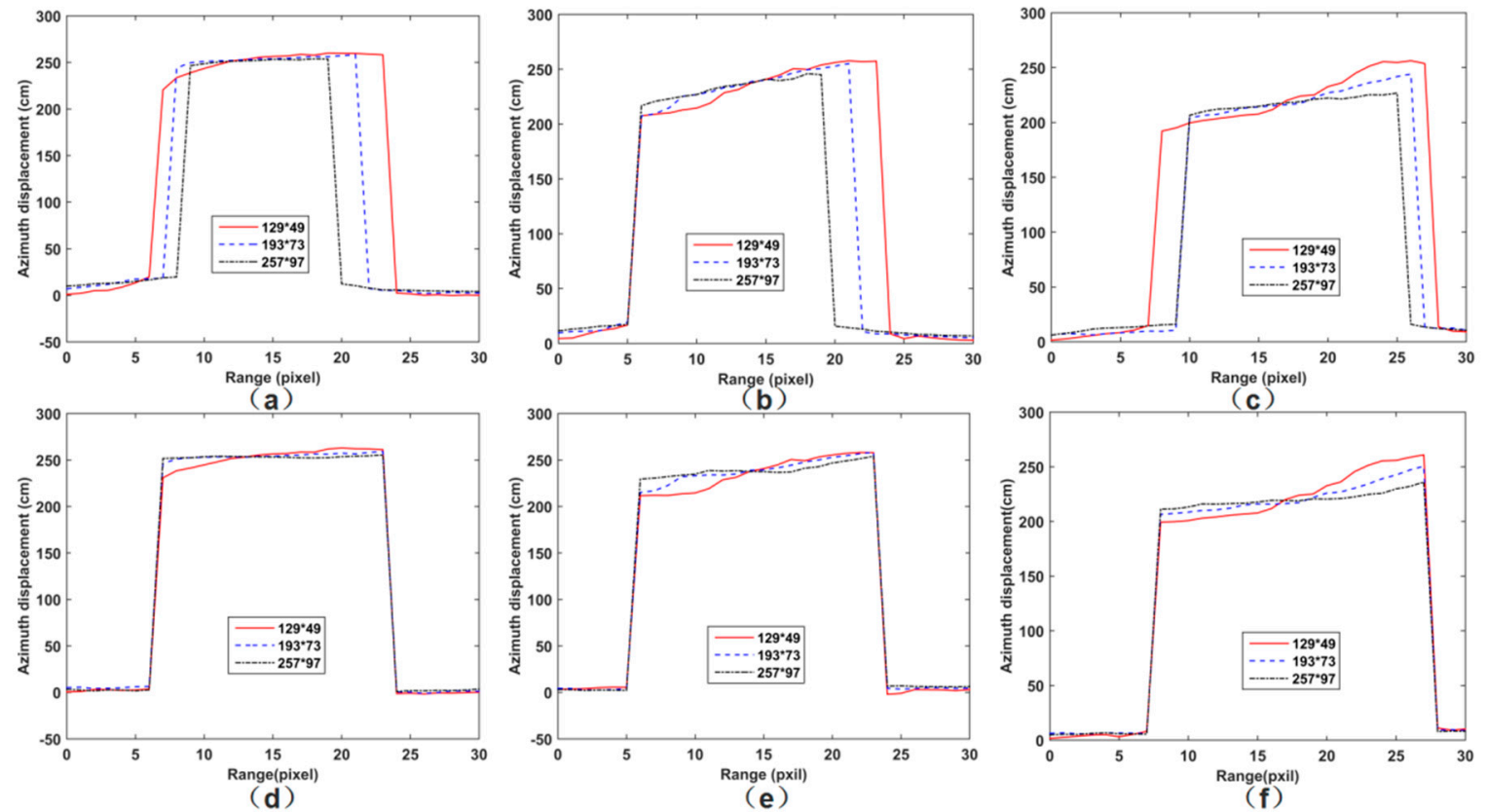

Figure 10. The azimuth displacements (19 August 2011 to 9 May 2012) profiles along lines K1, K2, and K3. The displacements are estimated by the classical NCC method $(\mathbf{a}-\mathbf{c})$ and the proposed ANCC method (d-f) under different size-matching windows. The red solid line, the blue dashed line, and the black dashed line are the estimation of matching windows with $129 \times 49$ pixels, $193 \times 73$ pixels, and $257 \times 97$ pixels, respectively. The classical NCC method indicates quite unstable estimations in the boundaries of the landslide.

Figure 11 presents the range displacements of the NCC method and the proposed ANCC method with the matching windows of $129 \times 49,193 \times 73$, and $257 \times 97$ pixels, respectively. As shown in Figure $11 \mathrm{a}-\mathrm{c}$, the range displacements near the boundaries of the landslide also become more blurred with the increasing matching window size. In the upper and lower parts of the landslide body in Figure $11 \mathrm{a}-\mathrm{c}$, with the increasing size of matching windows, some relatively stable areas (red rectangles) change to moving areas with much larger displacements. At the same time, some moving areas change to stable areas in the upper and middle parts of the landslide. This is obviously inconsistent with the facts. Also, as shown in Figure 12a-c, the range displacements estimated by the NCC method show severe unsteadiness on the edges of the landslide. On the contrary, the proposed ANCC method using different size-matching windows still obtain the detailed information of the displacements, as shown in Figure 11d-f, especially in the upper and lower parts of the landslide body. The range displacements profiles in Figure $12 \mathrm{~d}-\mathrm{f}$ also prove the stability of the proposed ANCC method. It is noted that the estimated displacements in the range direction are relatively worse than that in the azimuth direction for both NCC and ANCC methods. The main reason is that the images' pixel spacing in the range direction $(1.67 \mathrm{~m})$ is larger than that in the azimuth direction $(0.60 \mathrm{~m})$.

In addition, to further validate the proposed method, we select another pair of UAVSAR images with a shorter time span (9 May 2012 to 1 August 2012) for the experiment. Figures 13 and 14 show the azimuth and range displacement profiles along lines K1, K2 and K3, respectively. The results show that the estimations along the boundaries by the NCC method are changing with the increasing matching window size in both the azimuth (Figure 13a-c) and range (Figure 14a-c) directions. For the azimuth results of the ANCC (Figure 13d-f), the edges are stable, though the time span is much shorter. The range results of the ANCC (Figure 13d-f) method are relatively worse than the azimuth results, because of the much lower resolution. However, the range results of the ANCC present much better stability along the landslide boundaries than that of the classical NCC method. 


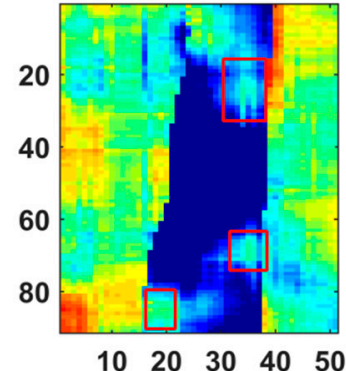

(a)

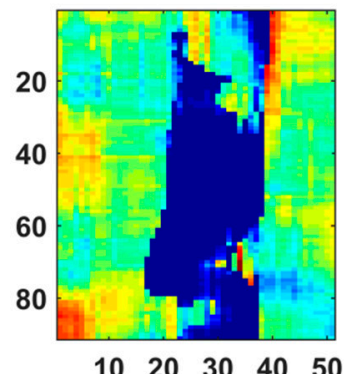

(d)



$\begin{array}{lllll}10 & 20 & 30 & 40 & 50\end{array}$

(b)

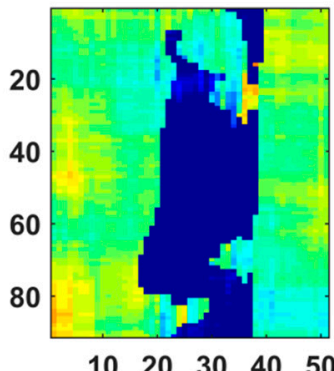

(e)

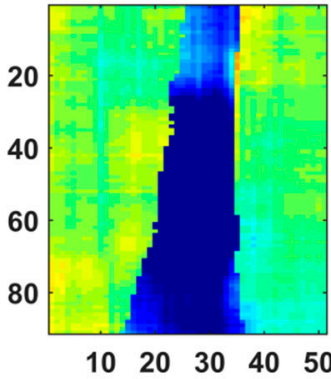

(c)

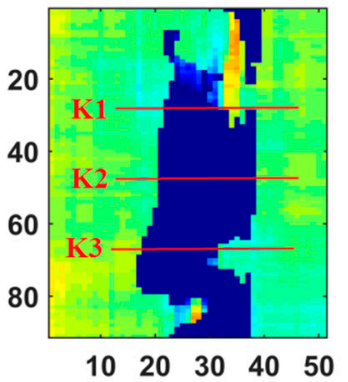

(f)

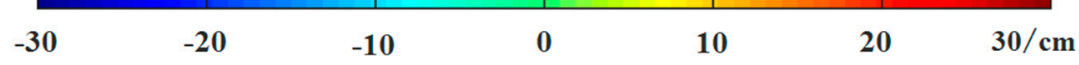

Figure 11. The range displacements (19 August 2011 to 9 May 2012) of sub-area A in Figure 5c. The displacements are estimated by the classical NCC method $(\mathbf{a}-\mathbf{c})$ and the proposed ANCC method (d-f) under different size-matching windows of $129 \times 49,193 \times 73$, and $257 \times 97$ pixels. The displayed range is also readjusted to $(-30,30) \mathrm{cm}$.
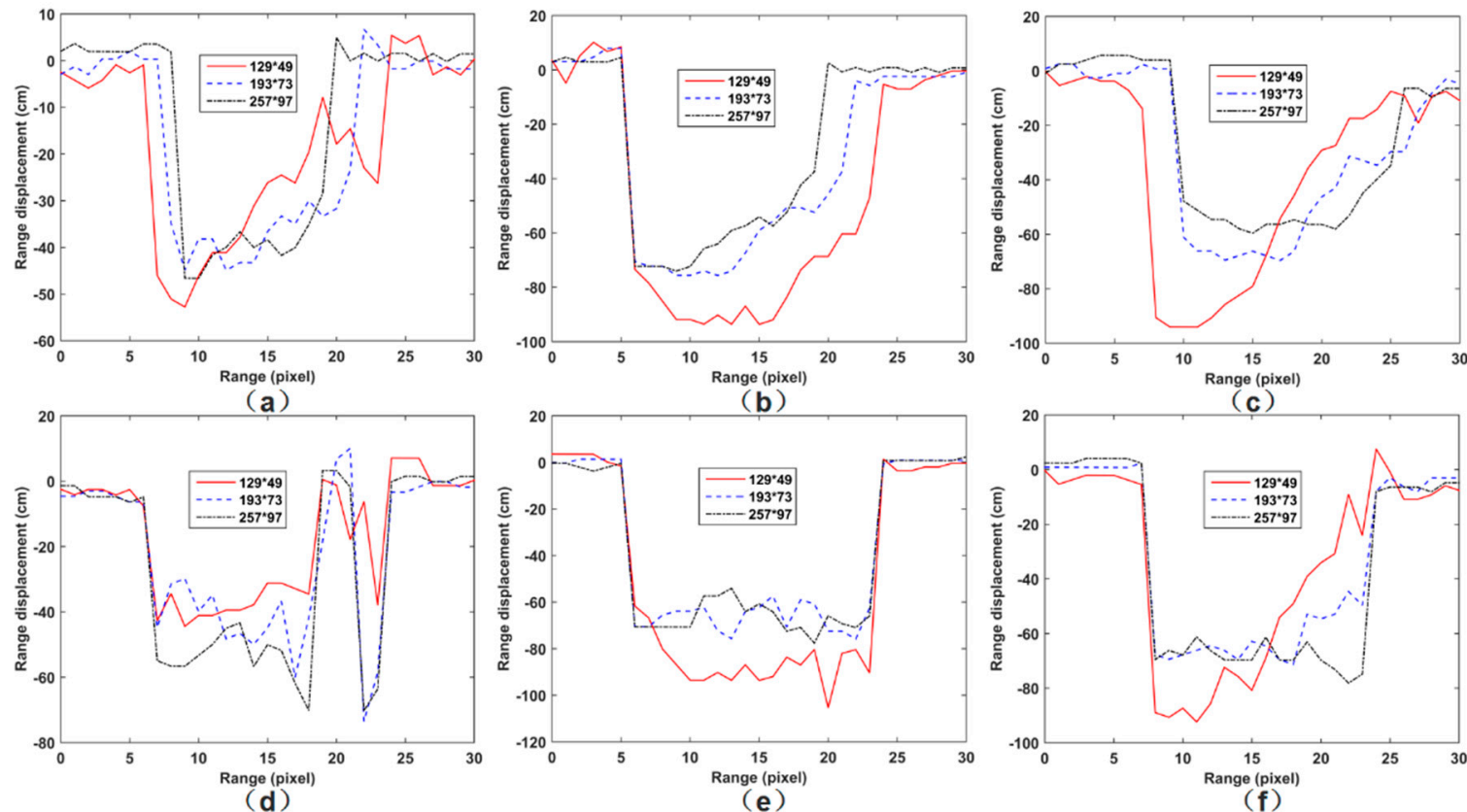

Figure 12. The range displacement (19 August 2011 to 9 May 2012) profiles along lines K1, K2, and K3. The displacements are estimated by the classical NCC method $(\mathbf{a}-\mathbf{c})$ and the proposed ANCC method (d-f) under different sizes of matching window. The classical NCC method also indicates quite unstable estimations in the boundaries of the landslide. 


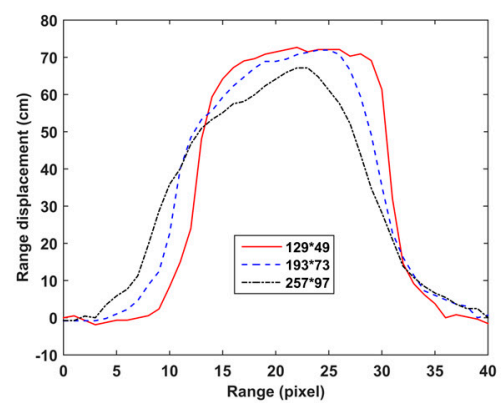

(a)



(d)

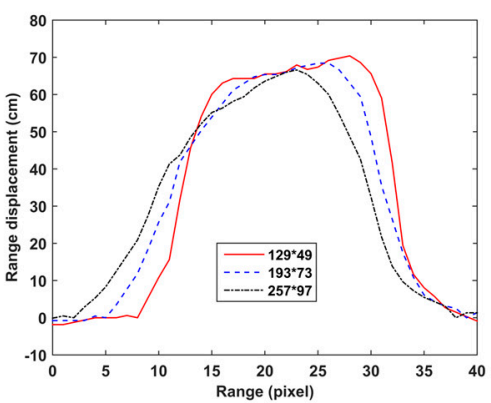

(b)

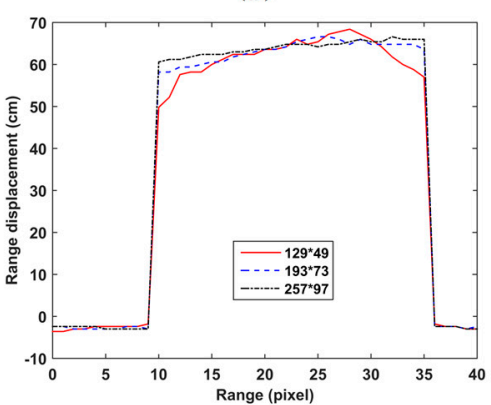

(e)

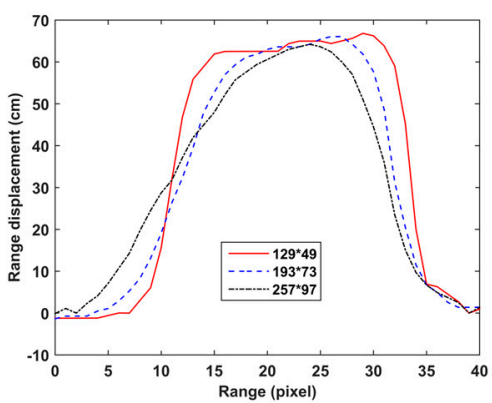

(c)

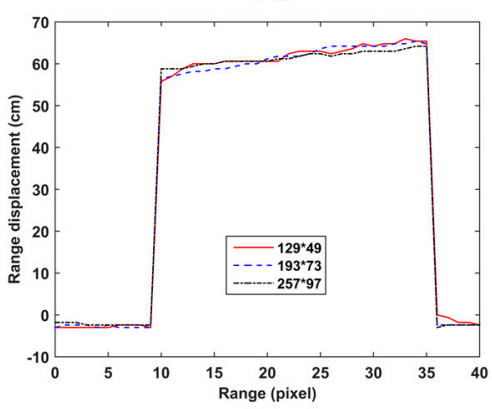

(f)

Figure 13. The azimuth displacement (9 May 2012 to 1 August 2012) profiles along lines K1, K2, and K3. The displacements are estimated by the classical NCC method $(\mathbf{a}-\mathbf{c})$ and the proposed ANCC method (d-f) under different size-matching windows. The classical NCC method shows quite unstable estimations in the boundaries of the landslide.

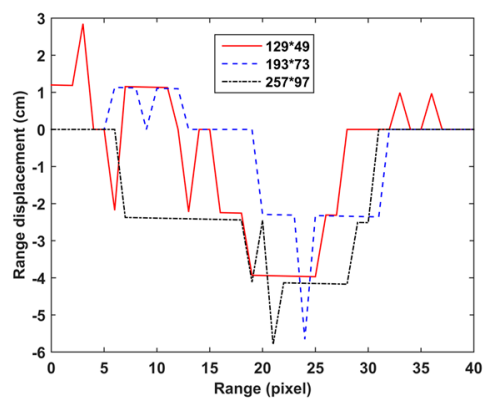

(a)

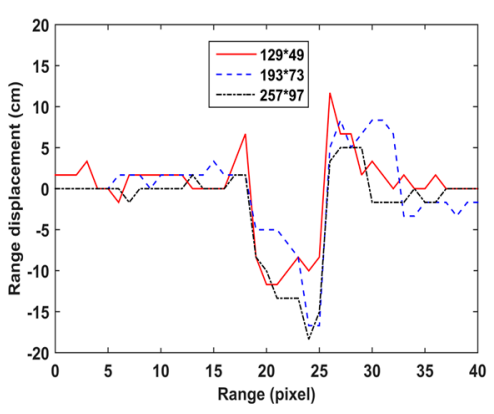

(d)

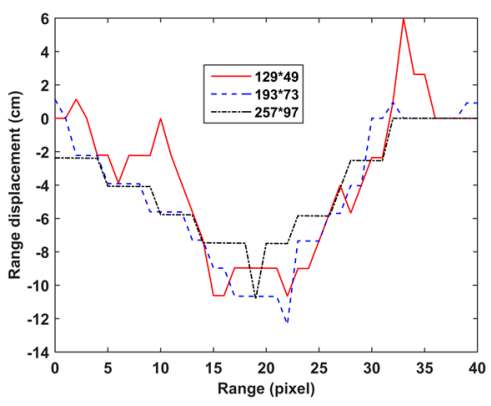

(b)

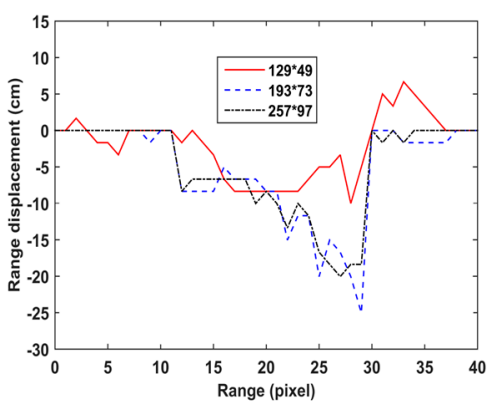

(e)

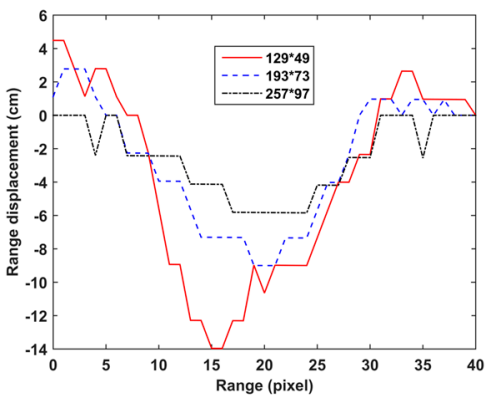

(c)

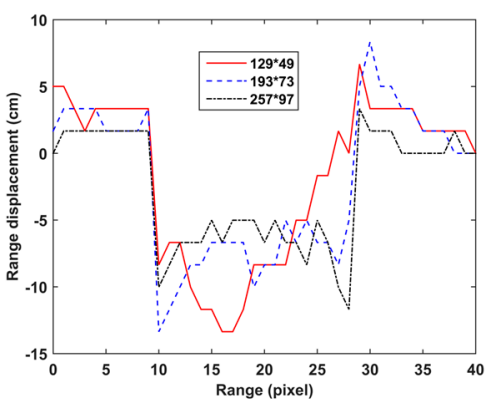

(f)

Figure 14. The range displacement (9 May 2012 to 1 August 2012) profiles along lines K1, K2, and K3. The displacements are estimated by the classical NCC method $(\mathbf{a}-\mathbf{c})$ and the proposed ANCC method (d-f) under different sizes of matching window. The classical NCC method also indicates quite unstable estimations in the boundaries of the landslide. 


\section{Conclusions}

This paper analyzes the principle of the classical offset tracking method (NCC) based on the regular window, and we find that it has lower accuracy in the boundary area. To address this problem, we propose a new offset tracking method (ANCC) based on adaptive windows. The proposed method generates adaptive matching windows according to each pixel's moving characteristics. We select a pair of high resolution UAVSAR polarimetric SAR datasets covering the Slumgullion landslide for experiments. The estimated displacements of the Slumgullion landslide show that the sliding velocity of the landslide ranges from 0.14 to $1.00 \mathrm{~cm} /$ day during the period of 19 August 2011 to 9 May 2012 . Then, we make comparisons between the classical NCC and the proposed ANCC methods from two aspects.

(1) First, we compare the cross-correlation coefficients of the best matched points for the NCC and the ANCC methods. The NCC has much lower correlation values on the landslide boundaries, as it uses regular matching windows, which contain different types of moving characteristics. In contrast, the ANCC method uses adaptive matching windows, including pixels with similar moving characteristics. Then, it can greatly improve the estimation accuracy of displacements for the landslide.

(2) Finally, we evaluate the stability with different size-matching windows for both methods. On the landslide boundaries, the displacements estimated by the classical NCC method are changing severely and become ambiguous with the increasing matching window size. In contrast, the proposed ANCC method has great stability in boundary areas, no matter the size of the matching window.

In conclusion, the ANCC method is more accurate and stable than the classical NCC method in the displacement monitoring on landslide boundaries. The ANCC method can be extended to other large displacement monitoring, such as glacier and volcano monitoring.

Acknowledgments: The work was supported by the National Natural Science Foundation of China (No. 41671356, 41371335 and 41531068), the Natural Science Foundation of Hunan Province, China (No. 2016JJ2141), the Planned Science and Technology Project of Hunan Province, China (No. 2016SK2003) and Innovation Foundation for Postgraduate of Central South University, China (No. 2017zzts768). The authors would like to thank Schulz William H. from USGS for providing GPS data and his helpful suggestions. The authors also thank NASA JPL for providing UAVSAR SAR images.

Author Contributions: Jiehua Cai performed the experiments, wrote and revised the paper; Changcheng Wang conceived the idea, designed the experiments, wrote and revised the paper; Xiaokang Mao and Qijie Wang analyzed the experimental results and revised the paper.

Conflicts of Interest: The authors declare no conflict of interest. The founding sponsors had no role in the design of the study; in the collection, analyses, or interpretation of data; in the writing of the manuscript, and in the decision to publish the results.

\section{References}

1. Petley, D.N. Global patterns of loss of life from landslides. Geology 2012, 40, 927-930. [CrossRef]

2. Greif, V.; Vlcko, J. Monitoring of post-failure landslide deformation by the PS-InSAR technique at Lubietova in Central Slovakia. Environ. Earth Sci. 2011, 66, 1585-1595. [CrossRef]

3. Singleton, A.; Li, Z.; Hoey, T.B.; Muller, J.P. Evaluating sub-pixel offset techniques as an alternative to D-InSAR for monitoring episodic landslide movements in vegetated terrain. Remote Sens. Environ. 2014, 147, 133-144. [CrossRef]

4. Rosen, P.A.; Hensley, S.; Joughin, I.; Li, F.; Madsen, S.N.; Rodriguez, E.; Goldstein, R.M. Synthetic aperture radar interferometry. Proc. IEEE 2000, 88, 333-382. [CrossRef]

5. Ferretti, A.; Prati, C.; Rocca, F. Multibaseline InSAR DEM Reconstruction: The Wavelet Approach. IEEE Trans. Geosci. Remote Sens. 1999, 37, 705-715. [CrossRef]

6. Rossi, C.; Gonzalez, F.R.; Fritz, T.; Yaguemartinez, N.; Eineder, M. TanDEM-X calibrated Raw DEM generation. ISPRS J. Photogramm. Remote Sens. 2012, 73, 12-20. [CrossRef] 
7. Khati, U.; Singh, G.; Ferro-Famil, L. Analysis of seasonal effects on forest parameter estimation of Indian deciduous forest using TerraSAR-X PolInSAR acquisitions. Remote Sens. Environ. 2017, 199, 265-276. [CrossRef]

8. Wang, C.; Wang, L.; Fu, H.; Xie, Q.; Zhu, J. The Impact of Forest Density on Forest Height Inversion Modeling from Polarimetric InSAR Data. Remote Sens. 2016, 8, 291. [CrossRef]

9. Marom, M.; Goldstein, R.M.; Thornton, E.B.; Shemer, L. Remote sensing of ocean wave spectra by interferometric synthetic aperture radar. Nature 1990, 345, 793-795. [CrossRef]

10. Colesanti, C.; Wasowski, J. Investigating landslides with space-borne Synthetic Aperture Radar (SAR) interferometry. Eng. Geol. 2006, 88, 173-199. [CrossRef]

11. Herrera, G.; Notti, D.; Garciadavalillo, J.C.; Mora, O.; Cooksley, G.; Sanchez, M.; Crosetto, M. Analysis with C- and X-band satellite SAR data of the Portalet landslide area. Landslides 2010, 8, 195-206. [CrossRef]

12. Liu, P.; Li, Z.; Hoey, T.B.; Kincal, C.; Zhang, J.; Zeng, Q.; Muller, J. Using advanced InSAR time series techniques to monitor landslide movements in Badong of the Three Gorges region, China. Int. J. Appl. Earth Obs. Geoinf. 2013, 21, 253-264. [CrossRef]

13. Herrera, G.; Fernandezmerodo, J.A.; Mulas, J.; Pastor, M.; Luzi, G.; Monserrat, O. A landslide forecasting model using ground based SAR data: The Portalet case study. Eng. Geol. 2009, 105, 220-230. [CrossRef]

14. Sun, Q.; Hu, J.; Zhang, L.; Ding, X. Towards Slow-Moving Landslide Monitoring by Integrating Multi-Sensor InSAR Time Series Datasets: The Zhouqu Case Study, China. Remote Sens. 2016, 8, 908. [CrossRef]

15. Gabriel, A.K.; Goldstein, R.M.; Zebker, H.A. Mapping small elevation changes over large areas: Differential radar interferometry. J. Geophys. Res. 1989, 94, 9183-9191. [CrossRef]

16. Bamler, R.; Eineder, M. Accuracy of differential shift estimation by correlation and split-bandwidth interferometry for wideband and delta-k SAR systems. IEEE Geosci. Remote Sens. Lett. 2005, 2, 151-155. [CrossRef]

17. Zhang, L.; Liao, M.; Balz, T.; Shi, X.; Jiang, Y. Monitoring Landslide Activities in the Three Gorges Area with Multi-frequency Satellite SAR Data Sets. In Modern Technologies for Landslide Monitoring and Prediction; Springer: Berlin/Heidelberg, Germany, 2015; pp. 181-208.

18. Mittermayer, J.; Wollstadt, S.J.; Prats, P.; Koppe, W. Staring spotlight imaging with TerraSAR-X. In Proceedings of the International Geoscience and Remote Sensing Symposium, Munich, Germany, 22-27 July 2012.

19. Milillo, P.; Riel, B.; Minchew, B.; Yun, S.; Simons, M.; Lundgren, P. On the Synergistic Use of SAR Constellations' Data Exploitation for Earth Science and Natural Hazard Response. IEEE J. Sel. Top. Appl. Earth Obs. Remote Sens. 2016, 9, 1095-1100. [CrossRef]

20. Ding, C.; Feng, G.; Li, Z.; Shan, X.; Du, Y.; Wang, H. Spatio-Temporal Error Sources Analysis and Accuracy Improvement in Landsat 8 Image Ground Displacement Measurements. Remote Sens. 2016, 8, 937. [CrossRef]

21. Michel, R.; Avouac, J.; Taboury, J. Measuring near field coseismic displacements from SAR images: Application to the Landers Earthquake. Geophys. Res. Lett. 1999, 26, 3017-3020. [CrossRef]

22. Fialko, Y.A.; Sandwell, D.T.; Simons, M.; Rosen, P.A. Three-dimensional deformation caused by the Bam, Iran, earthquake and the origin of shallow slip deficit. Nature 2005, 435, 295-299. [CrossRef] [PubMed]

23. Fielding, E.J.; Lundgren, P.R.; Taymaz, T.; Yolsalcevikbilen, S.; Owen, S.E. Fault-Slip Source Models for the 2011 M 7.1 Van Earthquake in Turkey from SAR Interferometry, Pixel Offset Tracking, GPS, and Seismic Waveform Analysis. Seismol. Res. Lett. 2013, 84, 579-593. [CrossRef]

24. Wang, T.; Wei, S.; Jónsson, S. Coseismic displacements from SAR image offsets between different satellite sensors: Application to the 2001 Bhuj (India) earthquake. Geophys. Res. Lett. 2015, 42, 7022-7030. [CrossRef]

25. Wang, T.; Jónsson, S. Improved SAR amplitude image offset measurements for deriving three-dimensional coseismic displacements. IEEE J. Sel. Top. Appl. Earth Obs. Remote Sens. 2015, 8, 3271-3278. [CrossRef]

26. Pritchard, H.D.; Murray, T.; Luckman, A.; Strozzi, T.; Barr, S. Glacier surge dynamics of Sortebræ, east Greenland, from synthetic aperture radar feature tracking. J. Geophys. Res. 2005, 110. [CrossRef]

27. Schubert, A.; Faes, A.; Kaab, A.; Meier, E. Glacier surface velocity estimation using repeat TerraSAR-X images: Wavelet- vs. correlation-based image matching. ISPRS J. Photogramm. Remote Sens. 2013, 82, 49-62. [CrossRef]

28. Neelmeijer, J.; Motagh, M.; Wetzel, H.-U. Estimating Spatial and Temporal Variability in Surface Kinematics of the Inylchek Glacier, Central Asia, using TerraSAR-X Data. Remote Sens. 2014, 6, 9239-9259. [CrossRef] 
29. Zhou, Y.; Li, Z.; Li, J. Slight glacier mass loss in the Karakoram region during the 1970s to 2000 revealed by KH-9 images and SRTM DEM. J. Glaciol. 2017, 63, 331-342. [CrossRef]

30. Bhattacharya, A.; Mukherjee, K.; Kuri, M.; Voge, M.; Sharma, M.L.; Arora, M.K.; Bhasin, R.K. Potential of SAR intensity tracking technique to estimate displacement rate in a landslide-prone area in Haridwar region, India. Nat. Hazards 2015, 79, 2101-2121. [CrossRef]

31. Giles, A.B.; Massom, R.A.; Warner, R.C. A method for sub-pixel scale feature-tracking using Radarsat images applied to the Mertz Glacier Tongue, East Antarctica. Remote Sens. Environ. 2009, 113, 1691-1699. [CrossRef]

32. Shi, X.; Zhang, L.; Balz, T.; Liao, M. Landslide deformation monitoring using point-like target offset tracking with multi-mode high-resolution TerraSAR-X data. ISPRS J. Photogramm. Remote Sens. 2015, 105, 128-140. [CrossRef]

33. Casu, F.; Manconi, A.; Pepe, A.; Lanari, R. Deformation Time-Series Generation in Areas Characterized by Large Displacement Dynamics: The SAR Amplitude Pixel-Offset SBAS Technique. IEEE Trans. Geosci. Remote Sens. 2011, 49, 2752-2763. [CrossRef]

34. Strozzi, T.; Luckman, A.; Murray, T.; Wegmuller, U.; Werner, C. Glacier motion estimation using SAR offset-tracking procedures. IEEE Trans. Geosci. Remote Sens. 2002, 40, 2384-2391. [CrossRef]

35. Derauw, D. DInSAR and Coherence Tracking Applied to Glaciology: The Example of Shirase Glacier. 1999. Available online: https://pdfs.semanticscholar.org/3012/0dabd7fbec77333db321b2de7cfe0b4604f6. pdf (accessed on 11 August 2017).

36. Zitova, B.; Flusser, J. Image registration methods: A survey. Image Vis. Comput. 2003, 21, 977-1000. [CrossRef]

37. Heid, T.; Kaab, A. Evaluation of existing image matching methods for deriving glacier surface displacements globally from optical satellite imagery. Remote Sens. Environ. 2012, 118, 339-355. [CrossRef]

38. Erten, E.; Reigber, A.; Hellwich, O.; Prats, P. Glacier Velocity Monitoring by Maximum Likelihood Texture Tracking. IEEE Trans. Geosci. Remote Sens. 2009, 47, 394-405. [CrossRef]

39. Erten, E.; Reigber, A.; Ferrofamil, L.; Hellwich, O. A New Coherent Similarity Measure for Temporal Multichannel Scene Characterization. IEEE Trans. Geosci. Remote Sens. 2012, 50, 2839-2851. [CrossRef]

40. Hu, X.; Wang, T.; Liao, M. Measuring coseismic displacements with point-like targets offset tracking. IEEE Geosci. Remote Sens. Lett. 2013, 11, 283-287. [CrossRef]

41. Wang, C.; Mao, X.; Wang, Q. Landslide Displacement Monitoring by a Fully Polarimetric SAR Offset Tracking Method. Remote Sens. 2016, 8, 624. [CrossRef]

42. Liu, J.; Iskander, M. Adaptive cross correlation for imaging displacements in soils. J. Comput. Civ. Eng. 2004, 18, 46-57. [CrossRef]

43. Rosen, P.A.; Hensley, S.; Wheeler, K.; Sadowy, G. UAVSAR: A new NASA airborne SAR system for science and technology research. In Proceedings of the IEEE Conference on Radar, Verona, NY, USA, 24-27 April 2006; p. 8.

44. Debellagilo, M.; Kaab, A. Sub-pixel precision image matching for measuring surface displacements on mass movements using normalized cross-correlation. Remote Sens. Environ. 2011, 115, 130-142. [CrossRef]

45. Schulz, W.H.; Mckenna, J.P.; Biavati, G.; Kibler, J.D. Characteristics of slumgullion landslide inferred from subsurface exploration, in-situ and laboratory testing, and monitoring. IEEE Trans. Geosci. Remote Sens. 2007, 44, 2861-2870.

46. Fleming, R.W.; Baum, R.L.; Giardino, M. Map and Description of the Active Part of the Slumgullion Landslide, Hinsdale County, Colorado; Geologic Investigations Series Map I-2672; U.S. Geological Survey: Reston, WV, USA, 1999.

47. Coe, J.A.; Ellis, W.L.; Godt, J.W.; Savage, W.Z.; Savage, J.E.; Michael, J.A.; Debray, S.K. Seasonal movement of the Slumgullion landslide determined from global positioning system surveys and field instrumentation. Eng. Geol. 2003, 68, 67-101. [CrossRef]

48. Coe, J.A. Regional moisture balance control of landslide motion: Implications for landslide forecasting in a changing climate. Geology 2012, 40, 323-326. [CrossRef]

49. Schulz, W.H.; Kean, J.W.; Wang, G. Landslide movement in southwest Colorado triggered by atmospheric tides. Nat. Geosci. 2009, 2, 863-866. [CrossRef]

50. Delbridge, B.G.; Burgmann, R.; Fielding, E.J.; Hensley, S. Kinematics of the slumgullion landslide from UAVSAR derived interferograms. In Proceedings of the International Geoscience and Remote Sensing Symposium, Milan, Italy, 26-31 July 2015; pp. 3842-3845. 
51. Milillo, P.; Fielding, E.J.; Shulz, W.H.; Delbridge, B.G.; Burgmann, R. COSMO-SkyMed Spotlight Interferometry Over Rural Areas: The Slumgullion Landslide in Colorado, USA. IEEE J. Sel. Top. Appl. Earth Obs. Remote Sens. 2014, 7, 2919-2926. [CrossRef]

52. Delbridge, B.G.; Burgmann, R.; Fielding, E.J.; Hensley, S.; Schulz, W.H. Three-dimensional surface deformation derived from airborne interferometric UAVSAR: Application to the Slumgullion Landslide. J. Geophys. Res. 2016, 121, 3951-3977. [CrossRef]

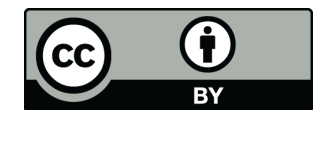

(C) 2017 by the authors. Licensee MDPI, Basel, Switzerland. This article is an open access article distributed under the terms and conditions of the Creative Commons Attribution (CC BY) license (http:/ / creativecommons.org/licenses/by/4.0/). 